\title{
Validação de construção de tissue microarray para estudo da displasia intraepitelial tubular renal
}

\author{
Validation of tissue microarray technique for intratubular epithelial dysplasia study
}

Andréa Lima Cruz Monnerat'; Maria Lúcia Ribeiro Caldas²; Andréa Rodrigues Cordovil Pires ${ }^{3}$

\begin{tabular}{|c|c|}
\hline & 0 \\
\hline $\begin{array}{l}\text { Carcinoma renal } \\
\text { Displasia intraepitelial } \\
\text { tubular renal } \\
\text { Tissue microarray } \\
\text { Antígeno Ki-67 } \\
\text { Proteína p53 }\end{array}$ & $\begin{array}{l}\text { Introdução e objetivo: O carcinoma de células renais (CCR) é umas das doenças urológicas de maior } \\
\text { malignidade, correspondendo a 1\%-3\% de todos os tumores sólidos dos adultos. As lesões pré-malignas } \\
\text { do CCR ainda não foram totalmente descritas. Achados de displasia intraepitelial tubular renal (DIETR) } \\
\text { em áreas próximas ao tumor, livres de neoplasia, sugerem que esta alteração possa ser a precursora } \\
\text { biológica de alguns tipos de CCR. O objetivo deste estudo é avaliar a possibilidade do uso de tissue } \\
\text { microarray (TMA) no estudo da DIETR e do CCR e os parâmetros para sua utilização imuno-histoquímica } \\
\text { (IHQ) utilizando os anticorpos anti-Ki-67 e p53 para confirmar a evidência de DIETR como precursora } \\
\text { biológica do CCR. Material e métodos: O estudo foi realizado em } 10 \text { peças cirúrgicas de nefrectomias } \\
\text { realizadas em pacientes com diagnóstico de CCR selecionadas no período de } 2000 \text { a 2005, em material } \\
\text { arquivado no Instituto Nacional de Câncer (INCA). Discussão: A utilização da técnica de TMA permite } \\
\text { amostragem de várias áreas e realização da IHQ utilizando apenas duas lâminas, uma para cada } \\
\text { marcador. Como não há na literatura descrição de utilização de TMA para estudo da DIETR, foi necessário } \\
\text { inicialmente realizar estudo de validação para saber se haveria representatividade de lesões focais no } \\
\text { TMA. Resultados: A análise estatística não mostrou diferença entre a utilização de TMA com dois ou } \\
\text { quatro cilindros de tecido ou o corte inteiro. Conclusão: O teste de validação de técnica artesanal de } \\
\text { TMA autorizou o uso de dois cilindros de } 1 \text { mm² por caso. }\end{array}$ \\
\hline
\end{tabular}

abstract

Introduction and objective: Renal cell carcinoma is one of the most malignant urological diseases, corresponding to $1 \%-3 \%$ of solid tumors in adults. The finding of intratubular epithelial dysplasia (IED) next to tumor areas suggests that this can be the biological precursor of some types of renal cell carcinoma (RCC). The objective of this study is to evaluate the use of tissue microarray (TMA) to study IED and RCC by immunohistochemistry (IHC) with Ki-67 and p53 protein to confirm the evidence that IED is the biological precursor of RCC. Material and method: This study was performed in archival material from ten nephrectomy surgical specimens from Instituto Nacional de Câncer, between 2000 and 2005. Discussion: TMA technique allows to sample and study several different areas from many patients in the same slide, using just one slide for each IHC marker. Once there was no previous study on IED by TMA, a validation test was needed first. Results: There was no statistical difference between 2 or 4 tissue cores and the whole section analysis. Conclusion: TMA validation assay demonstrated that the use of two tissue cores with $1 \mathrm{~mm}^{2}$ each was suitable to evaluate RCC and IED. key words

Renal cell carcinoma

Intratubular epithelial

dysplasia

Tissue microarray

Ki-67

p53 protein 


\section{Introdução}

Os carcinomas de células renais (CCR) representam cerca de $1 \%$ a $3 \%$ de todas as neoplasias malignas viscerais, sendo responsáveis por $90 \%$ dos cânceres renais em adultos de ambos os sexos. Existem cerca de 30 mil casos novos por ano e 12 mil mortes por esta doença. Os tumores ocorrem com maior frequência em indivíduos a partir dos 40 anos de idade, como a maioria dos tumores epiteliais, porém, a partir dos 75 anos, há queda da incidência, tanto em homens quanto em mulheres ${ }^{(7,17)}$.

A etiologia do CCR não está totalmente esclarecida e seu curso clínico é extremamente variável. A patogênese continua sendo assunto controverso na literatura e, mesmo com descrições de supostas alterações pré-malignas, muito pouco é conhecido sobre a biologia molecular destas lesões pré-cancerosas $^{(15)}$.

O nosso estudo objetiva validar a utilização de técnica artesanal de construção de tissue microarray (TMA) para caracterização de displasia intraepitelial tubular renal (DIETR) em casos de CCR para, posteriormente, avaliar cerca de 180 casos de CCR provenientes do Instituto Nacional de Câncer (INCA) no período de 2000 a 2005, utilizando esta técnica.

\section{Tissue microarray}

A primeira referência de produção de blocos de parafina com múltiplas amostras foi a "técnica da salsicha", na qual até 100 fragmentos de diferentes tecidos podiam ser agregados, envolvidos por membrana intestinal e processados para formar um bloco de parafina(2). Um ano depois, em 1987, surgiu a primeira descrição de punção de cilindros de tecido de blocos de parafina preexistentes, utilizando uma agulha hipodérmica convencional com a ponta cortada e organizando os 20 a 30 cilindros obtidos dentro de um canudo plástico de bebida para posterior inclusão em bloco de parafina ${ }^{(21)}$.

Estas técnicas foram aperfeiçoadas e, em 1998, foi publicado o primeiro artigo divulgando um equipamento comercial para puncionar cilindros de tecido de blocos de parafina de material de biópsias e necropsias (blocos doadores) e transferi-los para perfurações previamente realizadas pelo mesmo equipamento em um bloco de parafina receptor, com capacidade para até 1.000 amostras, denominado de tissue microarray (microbanco de tecido [TMA]) ${ }^{(11)}$. Após o desenvolvimento deste aparelho foram descritas outras técnicas de produzir TMA de forma artesanal $(5,6,12,14,16)$.
Uma preocupação natural com a utilização da técnica de TMA era sua validação, uma vez que os estudos eram realizados em uma pequena amostra, de 0,6 a $2 \mathrm{~mm}$, representando parte do material incluído em um bloco de parafina, que, por sua vez representava uma parte da lesão ou do órgão de origem. Diversos estudos avaliaram a significância estatística dos TMAs, aprovando sua utilização para pesquisas em larga escala populacional, particularmente em relação a tumores homogêneos ${ }^{(4,8,19)}$.

A possibilidade de analisar até 1.000 amostras em uma única lâmina de reação imuno-histoquímica ou de hibridização in situ, com validação estatística, causou grande impacto pela economia de tempo e do custo com reagentes dispendiosos, como anticorpos ou sondas. Outra vantagem importante é que cada bloco de TMA seria um "arquivo miniaturizado" de amostras anatomopatológicas, que poderia ser facilmente replicado e armazenado por centenas de anos, com preservação dos antígenos teciduais. Cada bloco de TMA pode fornecer cerca de 100 lâminas histopatológicas, permitindo numerosos estudos com os mesmos casos e estudos multi-institucionais com grande amostragem.

Rapidamente, os TMAs tornaram-se ferramentas de grande utilidade para pesquisa de novos critérios diagnósticos, fatores prognósticos e alvos moleculares para novas abordagens terapêuticas, além de controle de qualidade de técnicas de imuno-histoquímica e hibridização in situ ${ }^{(3,13,18)}$.

\section{Material e métodos}

\section{Identificação das áreas de displasia intraepitelial tubular renal}

A identificação histopatológica da DIETR utilizou os critérios de Mourad et al.(13): túbulos com núcleos volumosos, aumento da relação núcleo/citoplasma, hipercromasia, cromatina condensada e irregularidade na membrana nuclear (Figura 1). Deve ficar claro que não há estudos que comprovem que as áreas identificadas como DIETR sejam definitivamente displásicas, portanto podem corresponder a alterações reacionais. Esta avaliação foi realizada por três anatomopatologistas (uma patologista renal e duas patologistas gerais), de forma independente; as áreas selecionadas para inclusão no TMA foram escolhidas por consenso entre as três observadoras. A investigação imuno-histoquímica foi realizada para pesquisa do antígeno de proliferação nuclear Ki-67 (MIB1) e avaliação da expressão da proteína p53, marcadores frequentemente relacionados com a origem e a progressão de diversas neoplasias (sequência displasia-carcinoma), possíveis marcadores 
úteis para confirmar a evidência da DIETR como precursora biológica do CCR.

\section{Produção do bloco de tissue microarray}

Os tissue microarrays foram produzidos de acordo com a técnica descrita por Pires et al.(17), que consiste em um método artesanal embasado na construção de agulhas de TMA modificando agulhas hipodérmicas convencionais Becton-Dickinson PrecisionClide ${ }^{\circledR}$, utilizando uma microrretífica Dremel Multi-Pro ${ }^{\circledR}$ Rotary Tool Model 395, em rotação baixa $(<10.000 \mathrm{rpm})$, da seguinte forma: corte da ponta em bisel, abertura de janela lateral distando $1 \mathrm{~mm}$ da nova ponta e afiamentos externo e interno da ponta redonda para que esta possa cortar o bloco de parafina sem dano. Os cilindros de tecido foram obtidos por punção manual ou com agulha adaptada a uma máquina de colocação de ilhós; este procedimento "semiautomatizado" visa garantir puncionamento vertical rápido e seguro. Foram puncionados dois cilindros de tecido de cada caso, utilizando agulha com 1,19 mm de diâmetro $\left(S=\pi \mathrm{r}^{2}\right.$; área $\left.=1 \mathrm{~mm}^{2}\right)$. Os cilindros de tecido dos blocos doadores foram transferidos para um molde de inclusão de aço inoxidável, previamente preparado com uma grade produzida no programa de

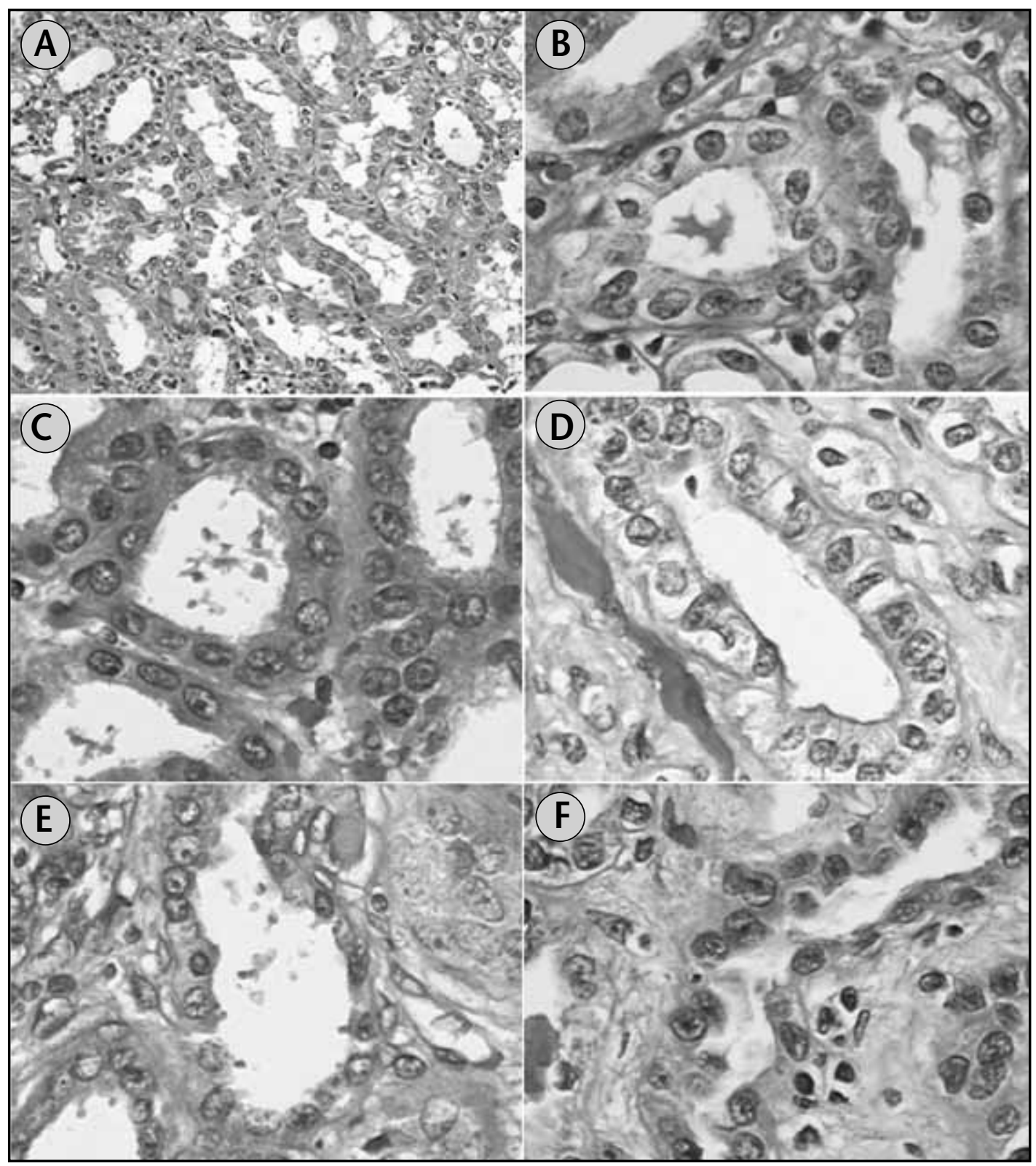

Figura 1 - DIETR: avaliação morfológica por HE

(A) Área displásica, panorâmina, objetiva de 10x; (B a F) alterações morfológicas da DIETR - aumento da relação núcleo: citoplasma, nucléolo evidente, binucleação e hipercromasia, objetiva de 40x HE: hematoxilina-eosina; DIETR: displasia intraepitelial tubular renal. 
desenho CorelDraw ${ }^{\circledast}$ e impressa em papel comum, com círculos brancos com $1 \mathrm{~mm}$ de diâmetro, espaçamento de $0,5 \mathrm{~mm}$ e coberta por fita adesiva de dupla face. Uma vez que todos os cilindros estavam aderidos à grade no molde, de forma alinhada e perpendicular, seguindo um mapa de orientação da localização de cada tecido no bloco, o molde foi preenchido por parafina líquida. Foi produzido um bloco de TMA contendo 10 casos de DIETR, com quatro cilindros de $1 \mathrm{~mm}^{2}$ por caso. Foram incluídos, além dos quatro cilindros de tecido dos casos para estudo, cilindros de tecido para utilização como controles positivos das reações imunohistoquímicas e orientação espacial do TMA (Figura 2).

O restante do procedimento técnico - microtomia, coloração por hematoxilina-eosina (HE) e imuno-histoquímica (IHQ) - foi realizado de forma convencional.

\section{Teste de validação do tissue microarray}

Áreas selecionadas de displasia tubular renal de 10 casos de CCR, próximas ou distantes da lesão tumoral, foram retiradas de blocos de parafina de tecido fixado em formol, produzindo um bloco de TMA com 40 cilindros de tecido (quatro cilindros de $1 \mathrm{~mm} 2$ de cada caso), que foi submetido a IHQ para avaliar a expressão de proteína p53 e antígeno Ki-67. O objetivo foi demonstrar a validação da técnica de TMA utilizando dois a quatro cilindros de tecido com $1 \mathrm{~mm}^{2}$ por caso para a análise da displasia tubular no carcinoma de células renais.

\section{Imuno-histoquímica}

Para as reações imuno-histoquímicas foram obtidos cortes histológicos do bloco de TMA com $4 \mu \mathrm{m}$ de espessura, em lâminas histológicas previamente tratadas com solução de silano (Allkimia), para garantir maior aderência do material à lâmina durante o processamento. Após desparafinizacão com solvente ecológico ECO-K (Clarus Technology), hidratação, bloqueio da peroxidase endógena e recuperação antigênica, foram aplicados os anticorpos primários, por 1 hora, em câmara úmida, seguidos do

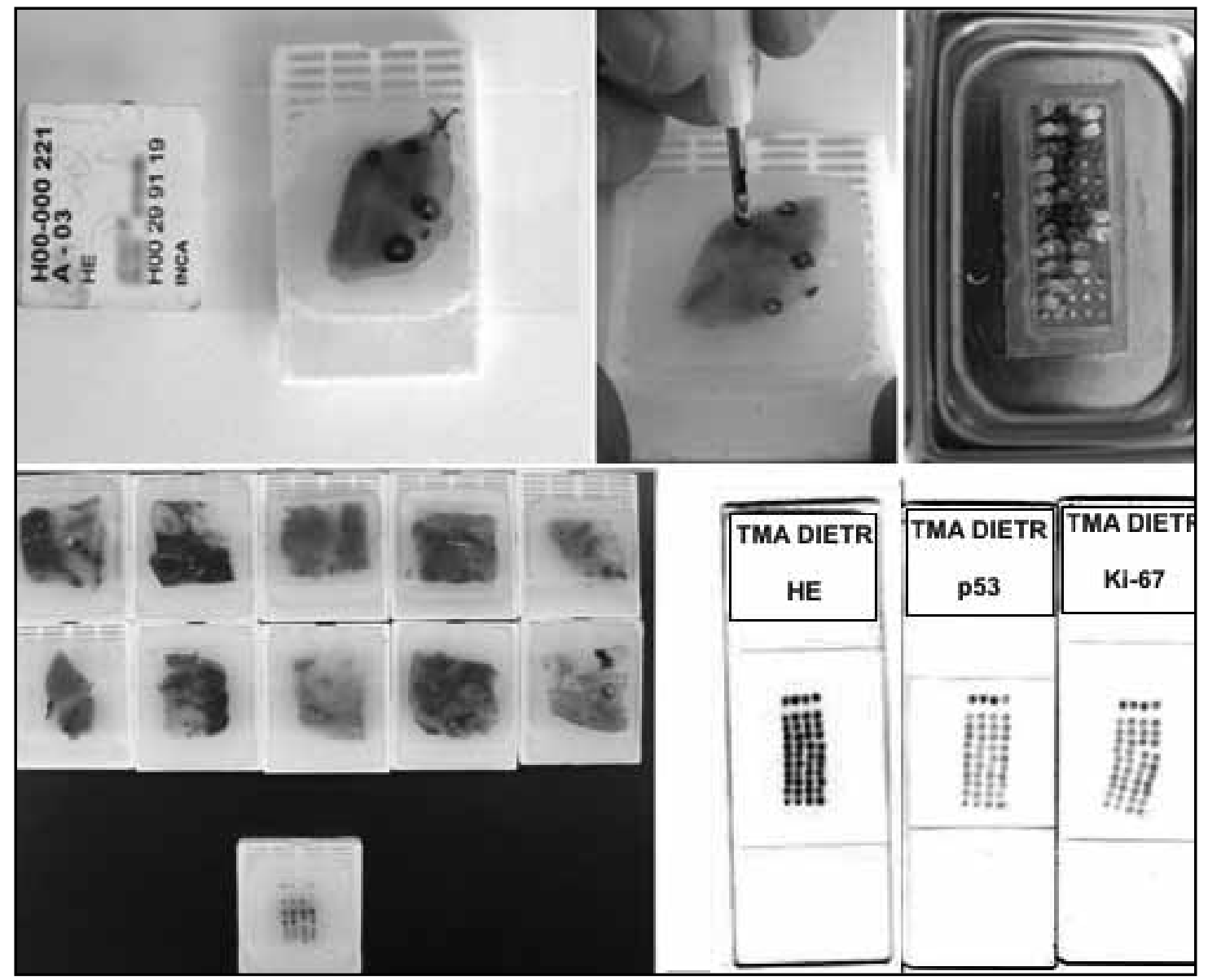

Figura 2 - Procedimento de construção dos blocos de TMA

Lâmina histopatológica corada por HE com áreas de interesse marcadas ( $x=$ DIETR e $0=C C R$ ), sobreposta ao respectivo bloco doador e posterior punção de área marcada; molde parcialmente preenchido pelos cilindros puncionados; blocos doadores e bloco de TMA resultante e lâminas de TMA - HE e IHQ com anticorpos antiproteína p53 e antígeno Ki-67

TMA: tissue microarray; HE: hematoxilina-eosina; DIETR: displasia intraepitelial tubular renal; CCR: carcinoma de células renais; IHQ: imuno-histoquímica. 
sistema de revelação/amplificação baseado em polímero livre de biotina Novolink (Novocastra/Vision Biosystems, Newcastle, Inglaterra), aplicação da solução cromógena diaminobenzidina ("liquid DAB-plus substrate kit", Zymed, código 00-2020) e contracoloração com hematoxilina de Harris (Merk).

As lâminas com cortes dos TMAs foram submetidas à IHQ com os seguintes anticorpos primários: proteína p53 (clone DO7, DAKOCytomation, Carpinteria, EUA; catálogo \#M7001, diluição 1:200) e antígeno Ki-67 (clone MIB1, DAKOCytomation, Carpinteria, EUA; catálogo \#M7240, diluição 1:100). Foram considerados positivos todos os núcleos celulares com coloração castanha moderada a intensa; estes foram contados em toda a área de cada cilindro examinado por duas patologistas, de forma independente. Em todas as lâminas havia controle negativo e positivo externo (pele normal para o antígeno Ki-67 e adenocarcinoma intestinal para a proteína p53).

\section{Análise estatística}

Os dados foram descritos estatisticamente por meio dos parâmetros: valor mínimo, valor máximo, mediana e intervalo interquartílico, além da média e do desvio padrão. A descrição gráfica utilizou diagramas de caixa e hastes (box plots). Comparações entre grupos de dados independentes foram realizadas pela técnica não paramétricas do teste de Mann-Whitney e a de dados pareados, pela técnica não paramétrica do teste de Wilcoxon. As decisões estatísticas foram tomadas ao nível de significância de 0,05 (5\%). A análise estatística foi realizada utilizando-se o software SPSS versão 10.0 e o aplicativo Excel (Microsoft).

\section{Resultados}

O bloco de TMA com 40 cilindros de tecido representando áreas de displasia tubular renal, identificadas pela

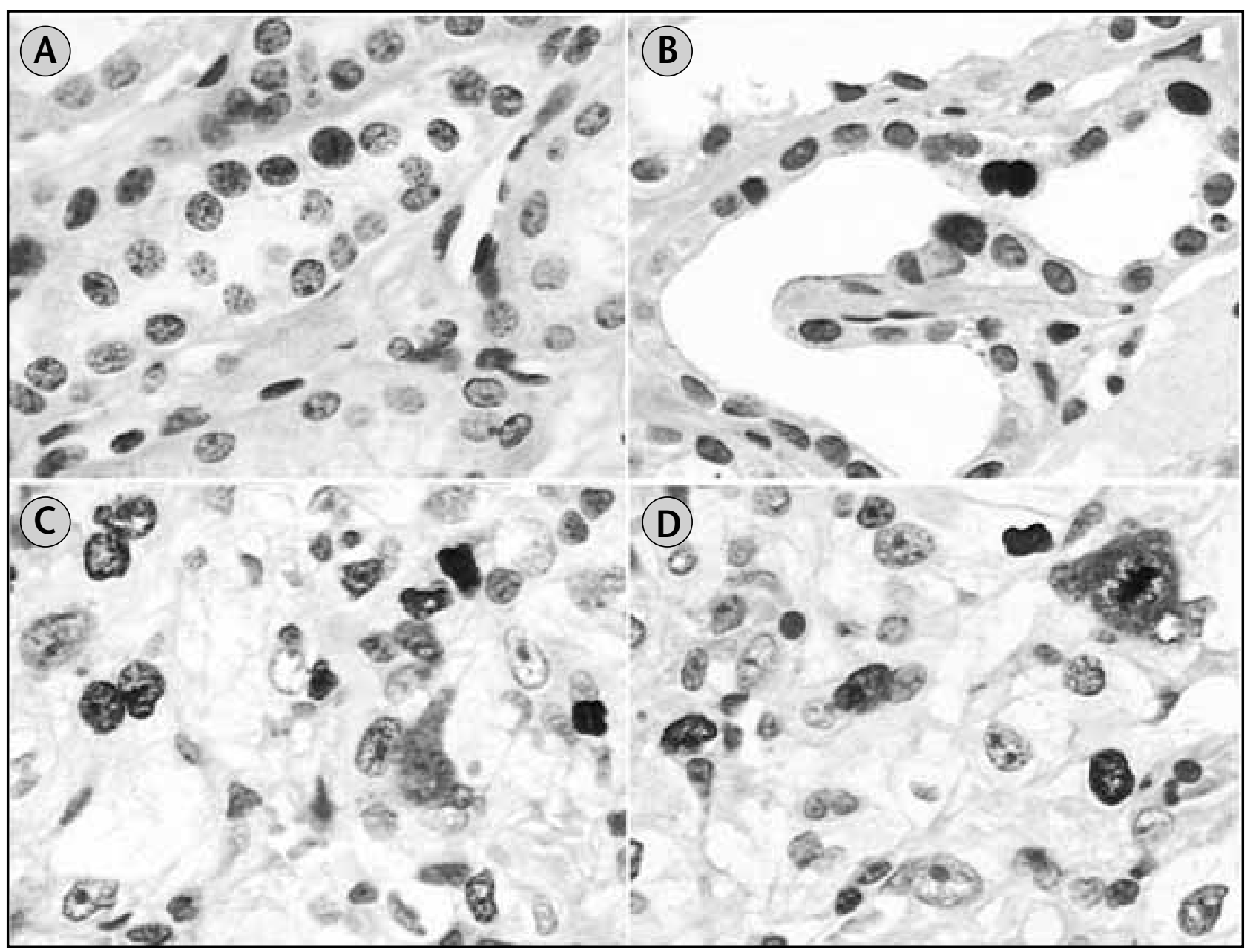

Figura 3 - (A) IHQ com o anticorpo antiproteína p53 - DIETR, marcação focal, objetiva de 40x; (B) IHQ com o anticorpo antiproteína p53 - DIETR, marcação moderada, objetiva de 40x; (C) IHQ com o anticorpo antiantígeno Ki-67 - DIETR, marcação difusa, objetiva de 40x; (D) IHQ com o anticorpo antiantígeno Ki-67 - DIETR com marcação focal, notar mitose positiva, objetiva de $40 x$

IHQ: imuno-histoquímica; DIETR: displasia intraepitelial tubular renal. 
histopatologia (quatro cilindros de $1 \mathrm{~mm}^{2}$ de cada caso) foi submetido a imuno-histoquímica para avaliar a expressão de proteína p53 e antígeno Ki-67 (Figura 3). Os resultados da imuno-histoquímica com os dois diferentes anticorpos, usando dois a quatro cilindros de tecido por caso $\left(1 \mathrm{~mm}^{2}\right.$ cada) e cortes inteiros na lâmina (área de $25 \mathrm{~mm}^{2}$ ) foram comparados.

A análise da proteína p53 mostrou diferença estatística significativa na comparação entre o TMA e cortes inteiros, favorecendo a utilização de dois cilindros de tecido $(p<0,05)$. Não houve diferença significativa entre as análises IHQs utilizando dois e quatro cilindros por caso $(p>0,05)$ (Tabela 1 e Figura 4).

A análise do antígeno Ki-67 não mostrou diferença estatística entre a utilização de TMA com dois ou quatro cilindros de tecido ou o corte inteiro (Tabela 2 e Figura 5).

Portanto, utilizando-se dois marcadores imuno-histoquímicos diferentes, ficou demonstrada a validação da técnica de TMA utilizando dois cilindros de tecido por caso, para a análise da displasia tubular no carcinoma de células renais.

\section{Tabela 1 Teste de validação do TMA: proteína p53}

\begin{tabular}{|c|c|c|c|}
\hline Caso & $2 \mathrm{~mm}^{2}$ & $4 \mathrm{~mm}^{2}$ & $25 \mathrm{~mm}^{2}$ \\
\hline H05-4690-B3 & $\begin{array}{c}1 \\
\text { cél/mm² }\end{array}$ & $\begin{array}{c}1,25 \\
\text { cél/mm² }\end{array}$ & $\begin{array}{c}0,32 \\
\text { cél//mm² }\end{array}$ \\
\hline H05-9853-A8 & 0 & $\begin{array}{c}0,25 \\
\text { cél/mm² }\end{array}$ & $\begin{array}{c}0,04 \\
\text { cél//mm² }\end{array}$ \\
\hline H05-1079-A4 & $\begin{array}{c}2 \\
\text { cél/mm² }\end{array}$ & $\begin{array}{c}1,75 \\
\text { cél/mm² }\end{array}$ & $\begin{array}{c}0,36 \\
\text { cél//mm² }\end{array}$ \\
\hline H05-2233-A4 & $\begin{array}{c}3 \\
\text { cél/mm² }\end{array}$ & $\begin{array}{c}2,75 \\
\text { cél/mm² }\end{array}$ & $\begin{array}{c}0,48 \\
\text { cél//mm² }\end{array}$ \\
\hline H05-2441-A8 & 0 & $\begin{array}{c}0,25 \\
\text { cél/mm² }\end{array}$ & $\begin{array}{c}0,16 \\
\text { cél//mm² }\end{array}$ \\
\hline H05-5553-B3 & $\begin{array}{c}2 \\
\text { cél//mm² }\end{array}$ & $\begin{array}{c}2,25 \\
\text { cél//mm² }\end{array}$ & $\begin{array}{c}0,24 \\
\text { cél//mm² }\end{array}$ \\
\hline H05-4099-A4 & $\begin{array}{c}0,5 \\
\text { cél//mm² }\end{array}$ & $\begin{array}{c}0,75 \\
\text { cél/mm² }\end{array}$ & $\begin{array}{c}0,12 \\
\text { cél//mm² }\end{array}$ \\
\hline H05-7838-A8 & $\begin{array}{c}2 \\
\text { él/mm² }\end{array}$ & $\begin{array}{c}2 \\
\text { cél/mm² }\end{array}$ & $\begin{array}{c}0,12 \\
\text { cél//mm² }\end{array}$ \\
\hline H05-5977-A7 & $\begin{array}{c}1 \\
\text { cél/mm² }\end{array}$ & $\begin{array}{c}1 \\
\text { cél } / \mathrm{mm}^{2}\end{array}$ & $\begin{array}{c}0,16 \\
\text { cél//mm² }\end{array}$ \\
\hline H05-6520-A6 & $\begin{array}{c}3 \\
\text { cél/mm² }\end{array}$ & $\begin{array}{c}3 \\
\text { cél/mm² }\end{array}$ & $\begin{array}{c}0,48 \\
\text { cél//mm² }\end{array}$ \\
\hline
\end{tabular}

\section{Discussão}

O presente estudo é parte inicial de um projeto maior, em que será analisada a DITR em casos de carcinoma de células renais. A avaliação imuno-histoquímica em cortes

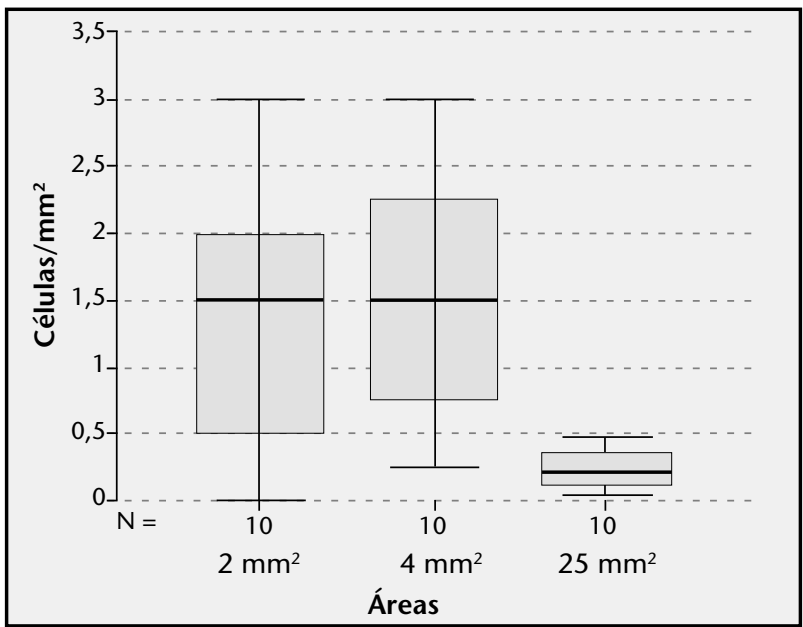

Figura 4 - Teste de validação do TMA: proteína p53 Teste t pareado

TMA: tissue microarray.

Tabela 2

Teste de validação do TMA: antígeno

\begin{tabular}{|c|c|c|c|}
\hline Caso & $2 \mathrm{~mm}^{2}$ & $4 \mathrm{~mm}^{2}$ & $25 \mathrm{~mm}^{2}$ \\
\hline H05-4690-B3 & $\begin{array}{c}3 \\
\text { cél/mm² }\end{array}$ & $\begin{array}{c}2,5 \\
\text { cél/mm² }\end{array}$ & $\begin{array}{c}1,32 \\
\text { cél } / \mathrm{mm}^{2}\end{array}$ \\
\hline H05-9853-A8 & 0 & $\begin{array}{c}0,25 \\
\text { cél/mm² }\end{array}$ & $\begin{array}{c}0,16 \\
\text { cél } / \mathrm{mm}^{2}\end{array}$ \\
\hline H05-1079-A4 & $\begin{array}{c}0,5 \\
\text { cél/mm² }\end{array}$ & $\begin{array}{c}0,75 \\
\text { cél/mm² }\end{array}$ & $\begin{array}{c}0,32 \\
\text { cél/ } / \mathrm{mm}^{2}\end{array}$ \\
\hline H05-2233-A4 & 0 & 0 & $\begin{array}{c}0,56 \\
\text { cél/ } / \mathrm{mm}^{2}\end{array}$ \\
\hline H05-2441-A8 & 0 & 0 & $\begin{array}{c}0,04 \\
\text { cél } / \mathrm{mm}^{2}\end{array}$ \\
\hline H05-5553-B3 & 0 & $\begin{array}{c}0,5 \\
\text { cél/mm² }\end{array}$ & $\begin{array}{c}0,04 \\
\text { cél } / \mathrm{mm}^{2}\end{array}$ \\
\hline H05-4099-A4 & 0 & 0 & $\begin{array}{c}1,16 \\
\text { cél//mm² }\end{array}$ \\
\hline H05-7838-A8 & $\begin{array}{c}0,75 \\
\text { cél/mm² }\end{array}$ & $\begin{array}{c}1,5 \\
\text { cél/mm² }\end{array}$ & $\begin{array}{c}1,56 \\
\text { cél/mm² }\end{array}$ \\
\hline H05-5977-A7 & $\begin{array}{c}1 \\
\text { cél/mm² }\end{array}$ & $\begin{array}{c}0,75 \\
\text { cél/mm² }\end{array}$ & $\begin{array}{c}0,64 \\
\text { cél } / \mathrm{mm}^{2}\end{array}$ \\
\hline H05-6520-A6 & $\begin{array}{c}1 \\
\text { cél/mm² }\end{array}$ & $\begin{array}{c}1,25 \\
\text { cél/mm² }\end{array}$ & $\begin{array}{c}0,36 \\
\text { cél } / \mathrm{mm}^{2}\end{array}$ \\
\hline
\end{tabular}




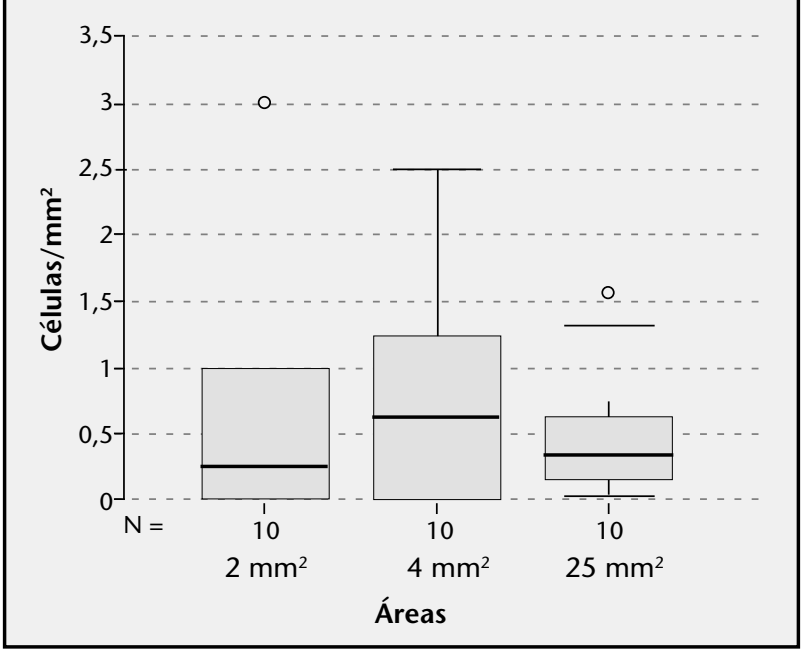

Figura 5 - Teste de validação do TMA: antígeno Ki-67 Teste do sinal

TMA: tissue microarray.

inteiros de blocos individuais com áreas displásicas e áreas de carcinoma em cerca de 180 casos, utilizando dois marcadores, resultaria em cerca de 360 lâminas, gerando um custo alto de reagentes e demandando grande tempo para sua avaliação. A utilização da técnica de TMA permite amostragem de todas essas áreas e realização da imuno-histoquímica utilizando apenas duas lâminas, uma para cada marcador. Como não há na literatura descrição de utilização de TMA para estudo da DITR, foi necessário inicialmente realizar estudo de validação para saber se haveria representatividade de lesões focais no TMA. Além de este ser o primeiro estudo usando TMA de áreas displásicas renais, é também o primeiro a utilizar a imuno-histoquímica com os anticorpos antiantígeno Ki-67 e a proteína $\mathrm{p} 53$ juntos. Zigeuner et al. ${ }^{(22)}$ avaliaram a expressão da proteína p53 e seu valor prognóstico em 188 CCRs de células claras primários e 58 metastáticos.
Visapää et al. ${ }^{(20)}$ realizaram um estudo com TMA em 257 casos de CCR células claras utilizando IHQ com o anticorpo antiantígeno Ki-67 como fator prognóstico. Além destes, foi publicado, em 2007, por Hager et al.(9), um trabalho com TMA com 461 casos de CCR para avaliar a perda de cilindros e, com isso, a perda do caso. No presente trabalho de validação não houve perda de cilindros. Foram também encontrados dois trabalhos utilizando TMA em CCR, porém um avaliou somente CCR cromófobo com outros marcadores que não o Ki-67 e a proteína p53, e o outro avaliou a expressão de bFGF em $\operatorname{CCR}^{(1,10)}$. Foi realizada busca, pelo sítio do periódico Capes (Pubmed/Bireme), de trabalhos relacionados com as seguintes palavras: TMA; $\mathrm{TMA}+$ dysplasia; TMA + renal cell carcinoma; TMA + renal dysplasia; TMA + kidney, onde só foram encontrados os trabalhos anteriormente descritos. Estes resultados não permitem ampla discussão, já que não foram encontrados, na literatura, dados estatísticos relacionados com o assunto nem em relação às comparações.

Os resultados obtidos neste estudo piloto validam a utilização da técnica de TMA artesanal descrita por Pires et al. ${ }^{(17)}$ para o estudo da DITR, permitindo a avaliação de centenas de casos em um único bloco, reduzindo acentuadamente os custos e o tempo do estudo.

\section{Conclusão}

Os resultados obtidos neste estudo piloto validam a utilização da técnica de TMA artesanal descrita por Pires et al.(17) no estudo da DIETR, utilizando dois cilindros de tecido com $1 \mathrm{~mm}^{2}$ cada, permitindo a avaliação de até centenas de casos em um único bloco, portanto reduzindo acentuadamente os custos e o tempo do estudo.

\section{Referências}

1. ABRAHAMS, N. A. et al. Chromofobe renal cell carcinoma: a comparative study of histological, immunohistochemical and ultrastrutural features using high throughput tissue microarray. Histopathol, v. 45, n. 6, p. 593-602, 2004.

2. BATTIFORA, H. The multitumor (sausage) tissue block: novel method for immunohistochemical antibody testing. Lab Invest, v. 55, n. 2, p. 244-8, 1986.

3. BRAUNSCHWEIG, T.; CHUNG, J. Y.; HEWITT, S. M. Tissue microarrays: bridging the gap between research and the clinic. Expert Rev Proteomics, v. 2, n. 3, p. 325-36, 2005.
4. CAMP, R. L.; CHARETTE, L. A.; RIMM, D. L. Validation of tissue microarray technology in breast carcinoma. Lab Investigation, v. 80, n. 12, p. 1943-9, 2000.

5. CHEN, N.; ZHOU, Q. Constructing tissue microarrays without prefabricating recipient blocks: a novel approach. Am J Clin Pathol, v. 124, p. 103-7, 2005.

6. DATTA, M. W. et al. A simple inexpensive method for the production of tissue microarrays from needle biopsy specimens. Appl Immunohistochem Mol Morphol, v. 13, n. 1, p. 96-103, 2005.

7. EBLE, J. N. et al. World Health Organization Classification of Tumors. Pathology and genetics. Tumors of the 
urinary system and male genital organs. Lyon: IARC Press 2004. p. 10-4.

8. GULMANN, C. et al. Biopsy of a biopsy: validation of immunoprofiling in gastric cancer biopsy tissue microarrays. Histopathology, v. 42, p. 70-6, 2003.

9. HAGER, M. et al. Tissue microarrays from renal cell tumors: exclusions criteria and rate of exclusion. Scand J Urol Nephrol, v. 41, n. 6, p. 485-9, 2007.

10. HORSTMANN, M. et al. Correlation of bFGF expression in renal cell cancer with clinical and histopathological features by tissue microarray analysis and measurement of serum levels. J Cancer Res Clin Oncol, v. 131, n. 11, p. 715-22, 2005.

11. KONONEN, J. et al. Tissue microarrays for high-throughput molecular profiling of tumor specimens. Nat Med, v. 4, n. 7, p. 844-7, 1998.

12. MATYSIAK, B. E. et al. Simple, inexpensive method for automating tissue microarray production provides enhanced microarray reproducibility. Appl Immunohistochem Mol Morphol, v. 11, n. 3, p. 269-73, 2003.

13. MOURAD, W. A. et al. Displastic tubular epithelium in "normal" kidney associated with renal cell carcinoma. Am J Surg Pathol, v. 18, p. 1117-24, 1994.

14. PACKEISEN, J. et al. Tissue microarray technology. J Clin Pathol: Mol Pathol, v. 56, p. 198-204, 2003.

15. PAN, C. C.; CHEN, P. C. H.; CHIANG, H. An easy method for manual construction of high-density tissue arrays.
Appl Immunohistochem Mol Morphol, v. 12, n. 4, p. 370-2, 2004.

16. PEHLIVAN, S. et al. Premalignant lesions of the kidney share the same genetics changes as conventional renal cell carcinoma. World J Urol, v. 22, n. 2, p. 120-3, 2004.

17. PIRES, A. R. C.; ANDREIUOLO, F. M.; SOUZA, S. R. A new method for the construction of tissue microarrrays without recipient paraffin block using custombuilt needles. Diagnostic Pathology, v. 1, p. 14, 2006. doi:10.1186/1746-1596-1-14. Disponível em: $<\mathrm{http}: / /$ www.diagnosticpathology.org/content/1/1/14>.

18. ROSAI, J. Rosai and Ackerman's surgical pathology. 9. ed. St Louis: Mosby, 2004. p. 1251-63.

19. VAN DE RIJN, M., GILKS, C. B. Applications of microarrays to histopathology. Histopathology, v. 44, p. 97-108, 2004.

20. VISAPÄÄ, H. et al. Correlation of $\mathrm{Ki}-67$ and gelsolin expression to clinical outcome in renal clear cell carcinoma. Urology, v. 61, p. 845-50, 2003.

21. WEN-HUI, W.; FORTUNA, M. B.; FURMANSKI, P. A rapid and efficient method for testing immunohistochemical reactivity of monoclonal antibodies against multiple tissue samples simultaneously. J Immunol Methods, v. 103, p. 121-9, 1987.

22. ZIGEUNER, R. et al. Value of p53 as a prognostic marker in histologic subtypes of renal cell carcinoma: a systematic analysis of primary and metastatic tumor tissue. Urology, v. 63, n. 4, p. 651-5, 2004.

23. ZIMPFER, A. et al. Construction and validation of a bone marrow tissue microarray. J Clin Pathol, v. 12, 2006. 